\title{
New herbal bitter liqueur with high antioxidant activity and lower sugar content: innovative approach to liqueurs formulations
}

\author{
Marija Petrović $^{1}$ (I) Predrag Vukosavljević ${ }^{2}$ Saša Đurović ${ }^{1} \cdot$ Mališa Antić $^{2}$ • \\ Stanislava Gorjanović ${ }^{1}$
}

Revised: 24 June 2019/Accepted: 11 July 2019/Published online: 23 July 2019

(C) Association of Food Scientists \& Technologists (India) 2019

\begin{abstract}
Herbal liqueurs are spirits with numerous functional properties, due to the presence of bioactive extractable compounds deriving from herbs. The aim of this study was to obtain new herbal bitter liqueur (HBL) on the basis of twelve selected bitter and aromatic plants extracts, with an optimal sensory profile for consumer acceptance. Also, the determination of optimal sugar content in HBL was done. Furthermore, antioxidant (AO) capacity and total phenolic content (TPC) of HBL was evaluated and compared to similar commercial herbal spirits. Among five tested formulations, assessed by 9-point hedonic scale, HBL with the ratio of bitter and aromatic plants 1:4 was the most acceptable. Ideal concentration of sugar in HBL, determined using a just-about-right scale, was found to be $80.32 \mathrm{~g} / \mathrm{l}$ of sucrose, which is approximately $20 \%$ less than the minimum stipulated by European Union Regulation and several times lower than in the majority of commercial liqueurs. Obtained result indicates the possibility of sugar reduction in liqueurs, and suggests the need to carry out sensory analysis before production of these high-calorie beverages. Radical scavenging ability against DPPH and ABTS radicals, as well as ferric reducing antioxidant power and TPC of HBL were convincingly superior in comparison to similar commercial herbal alcoholic beverages. High correlation coefficients between TPC and other assays applied strongly support the significant role of the polyphenols in the total AO capacity
\end{abstract}

Marija Petrović

marijapetrovic52@gmail.com

1 Institute of General and Physical Chemistry, Studentski trg 12-16, Belgrade, Serbia

2 Faculty of Agriculture, University of Belgrade, Nemanjina 6, Zemun, Belgrade 11080, Serbia of the HBL and other tested commercial herbal spirits. Headspace GC/MS revealed that the most abundant terpenes were menthone $(3.75 \%)$, eucalyptol $(3.42 \%)$ and menthol $(3.10 \%)$, whereas methanol was present in a small amount $(4.97 \mathrm{mg} / \mathrm{l})$.

Keywords Antioxidant activity $\cdot$ Herbal liqueur - Sensory analysis - Sucrose concentration - Total phenolic content

\section{Introduction}

Herbal liqueurs are descendants of former cordials, medicinal plants alcoholic extracts or elixirs that were believed to manifest curative properties. They were used exclusively for medicinal purposes and for enhancing general health condition. Although recipes for cordials can trace their roots back to Ancient Egypt, being inscribed on tombs walls, it seems that more known part of their history is associated with Middle Ages monasteries, where these elixirs were distilled and extracted by Italian and French monks. Some of today's worldwide famous liqueurs have been still produced in these monasteries' distilleries (Tonutti and Liddle 2010; Smith 2012).

Although alcoholic beverages have been associated with a negative connotation, the suggestion is that moderate daily consumption should be an integral part of human diet, with the specification that lower incidence of coronary heart diseases at adult moderate consumers appears to occur in comparison with non-drinkers (USDA 2005). Moreover, it was reported that drinking alcohol after meal contributes to the lower extent of absorption and increased alcohol elimination rates in healthy men and woman (Ramchandani et al. 2001). 
Liqueurs are spirits produced by flavoring distillate of various origin with aromatic components such as fruits, herbs and spices, nuts, flowers, etc., and sweetened with sugar, honey or other sweetening agents. In the production of herbal spirits different parts of herbs, as well as their isolates, such as essential oils and ethanolic extracts, distillates and rarely infusions have been used. Volatiles of the herbs are responsible for characteristic flavor (taste and aroma) and bouquet of the alcoholic beverage (Veljković and Stanković 2003). Blending more plant species when formulating herbal spirit is common, with one being the main contributor to final sensory properties of the product, whereas others are used for flavor or color corrections (Tonutti and Liddle 2010). For instance, bitter-tasting herbs are used for bitter spirits production alone or combined with aromatic ones. Bitter spirits are known for their aperitive and digestive effects, being consumed before a meal in order to stimulate the appetite or after a meal to aid food digestion, thus having a positive influence on human metabolism.

Liqueurs are high-calorie spirits, with a minimum $100 \mathrm{~g} / \mathrm{l}$ of sugar, expressed as inverted sugar, except for cherry liqueurs and those liqueurs made of gentian or similar plants as the sole flavoring substances, according to Regulation (EC) No. 110/2008. The most widely used sweetening agent is sucrose from beet or sugarcane, but others can also be used, such as honey, glucose syrup, high fructose corn syrup, etc. (European Parliament and Council 2008). Despite being sugar-sweetened and high-calorie spirits, replacement of carbohydrates in liqueurs with lowcalorie sweeteners has not still been considered in both science and worlds market of spirits. It seems that the main reason lies behind the concerns about the sensory quality of the product, associated with possible interference of sweetener and other compounds, as well as with influencing the body of the drink (Bamforth and Ward 2014). Besides, the addition of less than $100 \mathrm{~g} / \mathrm{l}$ of sugar is not allowed, whereas the upper level of sugar amount in liqueurs is not stipulated by Regulation. Therefore, sugar content in liqueurs often rises to the levels that are not popular among consumers, especially nowadays with increasing demand for lower calorie intake. Sugar-sweetened food and beverages have been shown to contribute to the weight gain and are associated with chronic health issues such as obesity, diabetes, cardiovascular disease, etc. (Ventura et al. 2011). World Health Organisation (WHO) strongly recommends sugar intake reduction in the amount of $10 \%$ of total calorie intake, and even better $5 \%$, or roughly $25 \mathrm{~g}$ (6 teaspoons) per day, for improvement of general health condition. As advised by WHO, policymakers and programme managers should assess the degree of free sugar intake in their countries in comparison to the standard, as well as to take appropriate actions in decreasing it where necessary, thus improving global public health. For instance, a major action would be reducing consumption of sugars is taxation of sugary drinks, which is already in force in some countries. This should have a positive influence on the food people choose to consume. Just as taxing tobacco helps to reduce tobacco use, taxing sugary drinks can help reduce consumption of sugars (World Health Organization 2015).

Therefore, reduction of sugar intake has become a key concern among consumers, leading to food products reformulation and potential regulatory adjustments, in which manufacturers can contribute largely through the development of sugar-reduced products. Although there is a growing interest for liqueurs in Europe, due to the trend of consumption after the meal and their benefits for metabolism, growing preference for healthy beverages may have a negative impact on the market of liqueurs in the future.

In addition to producing the feeling of pleasure, herbal spirits also contain a wide variety of bioactive compounds deriving from herbs. Taking into account that metabolism of alcohol leads to the production of hydroxyl radicals associated with potential liver damage (Albano 1996), natural AOs present in alcoholic beverages might be of special importance. Phenolic compounds extractable with a mixture of alcohol and water, present in various alcoholic beverages, including liqueurs, have attracted increasing attention, particularly with respect to the free radicals scavenging ability (Imark et al. 2000; Lee et al. 2005; Alamprese 2005; Paixao et al. 2007; Gorjanović et al. 2010a, b; Li and Beta 2011; Mrvcic et al. 2012; Yalcin 2016). Therefore, although alcoholic drinks cannot be classified as functional beverages, herbal spirits may be considered to exhibit functional properties.

This study was aimed to design new herbal bitter liqueur on the basis of selected medicinal plants, and to determine its ideal sweetness, on the basis of the sensory analysis, with consumers as the key judges. Functional properties of the obtained liqueur, in terms of its total phenolic content and AO potential, was evaluated and compared to the commercial alcoholic beverages of a similar type. Also, HS-GC/MS analysis was applied on HBL, mainly in terms of the determination of the qualitative and quantitative composition of some volatiles with possible toxicity such as methanol and higher alcohols.

\section{Materials and methods}

\section{Chemicals and commercial spirits}

Folin-Ciocalteu (FC) reagent, sodium carbonate, sodium acetate trihydrate, acetic acid, hydrochloric acid, aluminum 
chloride and sodium phosphate dibasic were of analytical grade, obtained from Merck, Darmstadt, Germany. DPPH (2,2-diphenyl-1-picrylhydrazyl) was produced by Fluka (Buchs, Switzerland), methanol was obtained from J.T. Baker (Deventer, Netherlands). Trolox (6-hydroxy-2,5,7,8tetramethylchromane-2-carboxylic acid), 2,4,6-tripyridylS-triazine (TPTZ) and 2,2'-azino-bis(3-ethylbenzthiazoline-6-sulfonic acid diammonium salt (ABTS) were from Sigma-Aldrich, Munich, Germany. Ethanol 96\% (v/v) was obtained from Ada vrenje (Serbia, Belgrade). Various herbal spirits of different origin, either domestic or imported, were purchased from Serbian markets, whereas medicinal tonic Pervivo was purchased in a pharmacy.

\section{Plant extracts preparation}

Twelve medicinal plants, regularly used in the alcoholic beverages industry, were selected for HBL formulation and have been divided in two groups. First group consists of bitter (including bitter-aromatic) plants, with considerable amount of bitter components and of predominately bitter taste, such as Teucrium montanum (Mountain Germander), Teucrium chamaedrys (Wall germander), Gentiana lutea (Gentian), Artemisia absinthium (Wormwood), Centaurium erythraea (Centaury) and Tussilago farfara (Coltsfoot). The second group are aromatic plants, with intense aroma originating from the essential oils, as plants' active principles, such as Salvia officinalis (Sage), Mentha piperita (Mentha), Pimpinella anisum (Aniseed), Lavandula officinalis (Lavender), Foeniculum vulgare (Fennel fruits), Coriandrum sativum (Coriander). Selected plants were collected from the cultivating fields of "Bilje Borča" company (Belgrade-Serbia) located in various regions of Serbia, during 2012. Air-dried and finely ground plant material was extracted according to the European Pharmacopoeia (Council of Europe 1999) by continual maceration with the water-ethanol solution $(65 \% \mathrm{v} / \mathrm{v})$, employing the percolation vessel for a period of $48 \mathrm{~h}$, at room temperature $\left(20{ }^{\circ} \mathrm{C}\right)$. The remaining soaked herbs were separated from the extracts by filtration and were mechanically pressed. The extracts were clarified by filtration and adjusted to a ratio of 1:5 (dry plant material: solvent).

\section{Herbal bitter liqueur preparation}

In order to obtain HBL with the most acceptable sensory properties, five combinations of extracts, with the ratios of $1: 1,1: 2,1: 3,1: 4$ and 1:5 of bitter and aromatic plants extracts were initially tested. Due to its appealing and generally accepted aroma, Mentha extract was decided to represent half of the total amount of aromatic extracts. Obtained formulations were diluted with water to a final
$25 \%$ of ethanol and filtered using filter Filtrox Fibrafix "AF31H". Glycerol, as a viscous polyalcohol of a slightly sweet taste, was added in the amount of $2 \mathrm{ml} / 1$ in order to contribute to the body and fullness of the beverage. Finally, the minimum stipulated concentration of sucrose $(100 \mathrm{~g} / \mathrm{l})$ in accordance with Regulation (EC) No. 110/2008 was added to obtain liqueurs with a preliminary sweetness, ready for consumer opinion evaluation.

\section{Hedonic test}

The hedonic test was performed in order to choose formulation with the most acceptible sensory characteristics. Group of 100 non-trained occasional consumers of herbal spirits (55 men and 45 women), recruited on the Faculty of Agriculture, University of Belgrade, Serbia, were instructed to evaluate the degree of acceptability of the sensory attributes such as colour, odor, bitterness, mint flavour, anise flavour and overall acceptability using 9-point hedonic scale (1: dislike extremely; 9: like extremely) (Meilgaard et al. 2007; Lawless and Heymann 2010).

\section{Ideal sweetness determination}

The ideal concentration of sucrose to be added in the HBL was determined by the acceptance test, using the just about right (JAR) scale (Meilgaard et al. 2007) by the same panelists who performed the hedonic analysis. The HBL samples with five sucrose concentrations $(50 \mathrm{~g} / \mathrm{l}, 70 \mathrm{~g} / \mathrm{l}$, $90 \mathrm{~g} / \mathrm{l}, 110 \mathrm{~g} / \mathrm{l}, 130 \mathrm{~g} / \mathrm{l})$, below and above the minimum stipulated by Regulation (EC) No. 110/2008, were served to the subjects in order to evaluate the sweetness by placing a mark in one of the boxes of a nine-category scale from 'not nearly sweet enough' $=-4$, to 'much too sweet' at the other extreme $=+4$, and 'just right' in the middle (corresponding to zero). The samples were presented monadically in disposable plastic cups coded with threedigit numbers, using a balanced complete block design (Wakeling and MacFie 1995).

The results were analyzed by histograms with the sensory response distribution in percentages with respect to the sucrose concentrations. Also, a simple linear regression between the means of the values assigned by consumers and sucrose concentrations allowed calculating the exact concentration of sucrose to be added for ideal sweetness.

\section{Determination of total phenolic content}

Folin-Ciocalteu assay was applied for the determination of total phenolic content (Singleton et al. 1999). Properly diluted samples $(0.5 \mathrm{ml})$ were mixed with $0.1 \mathrm{M} \mathrm{FC}$ reagent $(2.5 \mathrm{ml})$ and after $6 \mathrm{~min}$ reacting in the dark, sodium carbonate solution $(75 \mathrm{~g} / \mathrm{l})$ in the amount of $2.5 \mathrm{ml}$ 
was added. The mixture was allowed to stand $2 \mathrm{~h}$ in the dark. Finally, absorbance at $740 \mathrm{~nm}$ was measured, using the respective solvent as a blank. The results were expressed as mg GA equivalent (GAE) per liter of the sample and presented as mean \pm standard deviation of triplicate analysis.

\section{Antiradical activity determination by DPPH assay}

Antiradical activity of samples against DPPH radical was measured by the modified method of (Blois 1958). Diluted samples $(0.2 \mathrm{ml})$ were mixed with $2.8 \mathrm{ml}$ of the ethanolic solution of DPPH $(0.1 \mathrm{mM})$ mixed with acetate buffer $(0.1 \mathrm{M})$ in the ratio $2: 1$. The mixture was allowed to react $30 \mathrm{~min}$ in the dark before measurement absorbance at $517 \mathrm{~nm}$ against the blank (ethanol). The results are expressed as millimoles of Trolox equivalents per liter of the sample $(\mathrm{mM} \mathrm{TE} / \mathrm{l})$. Triplicate measurements were performed.

\section{Determination of total reducing power by FRAP}

The ferric reducing antioxidant power (FRAP) assay was performed according to the procedure previously described with some modification (Benzie and Strain 1996). Diluted samples $(0.1 \mathrm{ml})$ were mixed with distilled water $(0.3 \mathrm{ml})$ and freshly made FRAP reagent $(3 \mathrm{ml})$. After $40 \mathrm{~min}$ of incubation at $37{ }^{\circ} \mathrm{C}$ absorbance was measured against the reagent blank at $593 \mathrm{~nm}$. The results were expressed as $\mathrm{mM}$ Trolox equivalents per liter of the sample (mM TE/l). Measurements were done in triplicate.

\section{Antiradical activity determination by ABTS assay}

Antiradical activity of herbal spirits against ABTS radical was measured by the method described previously, with some modifications (Re et al. 1999). A working $\mathrm{ABTS}^{+}$ solution was obtained by diluting $\mathrm{ABTS}^{+}$stock solution (14 mM of ABTS and $4.9 \mathrm{mM}$ potassium persulphate in a phosphate buffer $\mathrm{pH}$ 7.4) with phosphate buffer to obtain an absorbance of $0.70 \pm 0.02$ at $734 \mathrm{~nm}$. Several concentrations of the sample $(0.3 \mathrm{ml})$ were mixed with working $\mathrm{ABTS}^{+}$solution and the absorbance was measured after 6 min. Trolox equivalent AO capacity (TEAC) was calculated using the following equation: TEAC (mM $\mathrm{TE})=($ Gradient of sample dose-response curve/Gradient of Trolox dose-response curve).

\section{HS-GC/MS analysis}

Headspace (HS) GC/MS analysis was performed using Thermo Fisher Focus GC combined with Polaris Q mass spectrometer and TriPlus HS autosampler. A certain volume of sample $(1 \mathrm{ml})$ was sealed into HS vial. Incubation time was $15 \mathrm{~min}$ at $80{ }^{\circ} \mathrm{C}$. After incubation, $1 \mathrm{ml}$ of the gas phase was injected into GC and analyzed. Colum was TR WAX-MS $(30 \mathrm{~m} \times 0.25 \mathrm{~mm}, 0.20 \mu \mathrm{m})$. The temperature program was as follows: initial temperature $50{ }^{\circ} \mathrm{C}$ ( $3 \mathrm{~min}$ ), then $5{ }^{\circ} \mathrm{C} / \mathrm{min}$ to $130{ }^{\circ} \mathrm{C}$ and $15^{\circ} \mathrm{C} / \mathrm{min}$ to $240{ }^{\circ} \mathrm{C}$. Temperatures of the injector, MS transfer line and ion source were $240{ }^{\circ} \mathrm{C}, 240{ }^{\circ} \mathrm{C}$ and $240{ }^{\circ} \mathrm{C}$, respectively. Helium was used as a carrier with a flow of $1.5 \mathrm{ml} / \mathrm{min}$ in split mode (30:1). The final result was expressed as a relative percentage (\%), while methanol and ethyl acetate content were expressed in milligrams per liter of the sample $(\mathrm{mg} / \mathrm{l})$.

\section{Statistical analysis}

Descriptive statistical analyses were performed using Microsoft Excel 2007 software for the means and the standard error of the mean calculation. The results are expressed in the form of mean \pm standard deviation (SD). The evaluation of analysis of variance (ANOVA), and F-test of obtained results were performed for comparison of means, and significant differences between samples are determined by post hoc Tukey's HSD test at 95\% confidence limit, using StatSoft Statistica 10 software.

\section{Results and discussion}

\section{Hedonic test}

The hedonic test was performed to evaluate consumers' opinion on five liqueurs with different proportions of bitter and aromatic plant extracts, sweetened with a preliminary amount of sucrose $(100 \mathrm{~g} / \mathrm{l})$, as the minimum stipulated by European Union Regulation. Sensory attributes (color, odor, bitterness, mint flavor, anise flavor and overall acceptability) were chosen on the basis of the preliminary evaluation of the samples, by the panel of experts in the field of sensory analysis of alcoholic beverages (Faculty of Agriculture, University of Belgrade, Serbia). Mint flavor, associated with cooling and refreshing sensations, and anise flavor with its strong, sweet, licorice-like dimension, were selected as the most pronounced flavors in HBL, originating from menthol and anethole, the most abundant volatile compounds of the plants Mentha and Aniseed.

Results are shown in Table 1. Liqueur HBL with the ratio 1:4 of bitter and aromatic plants was assigned with significantly higher scores $(p<0.05)$ for odor, anise flavor and overall acceptability when compared with the other formulations. The trend of increasing the sensory scores for bitterness and mint flavor with increasing the amount of aromatic plants extracts can be observed. According to the 
Table 1 Results of acceptability evaluation of different herbal liqueur formulations obtained by hedonic test

\begin{tabular}{|c|c|c|c|c|c|c|}
\hline \multirow[t]{2}{*}{ Formulations } & \multicolumn{6}{|c|}{ Sensory attributes } \\
\hline & Odor & Colour & Bitterness & Mint flavor & Anise flavor & Overall acceptability \\
\hline HBL 1:1 & $5.61 \pm 1.72^{\mathrm{a}}$ & $6.21 \pm 1.54^{\mathrm{a}}$ & $3.22 \pm 1.53^{\mathrm{a}}$ & $4.91 \pm 1.93^{\mathrm{a}}$ & $4.5 \pm 1.25^{\mathrm{a}}$ & $3.3 \pm 1.72^{\mathrm{a}}$ \\
\hline HBL 1:2 & $5.69 \pm 1.42^{\mathrm{a}}$ & $6.08 \pm 1.66^{\mathrm{a}}$ & $3.31 \pm 1.56^{\mathrm{a}}$ & $4.82 \pm 1.22^{\mathrm{a}}$ & $4.45 \pm 0.95^{\mathrm{a}}$ & $4.1 \pm 1.42^{\mathrm{b}}$ \\
\hline HBL $1: 3$ & $5.92 \pm 1.6^{\mathrm{a}}$ & $6.21 \pm 1.54^{\mathrm{a}}$ & $4.62 \pm 1.19^{\mathrm{b}}$ & $5.71 \pm 1.04^{\mathrm{b}}$ & $5.39 \pm 1.29^{\mathrm{b}}$ & $5.62 \pm 1.6^{\mathrm{c}}$ \\
\hline HBL 1:4 & $6.27 \pm 1.62^{\mathrm{a}}$ & $6.17 \pm 1.79^{\mathrm{a}}$ & $5.68 \pm 1.37^{\mathrm{c}}$ & $6.55 \pm 1.55^{\mathrm{c}}$ & $6.12 \pm 1.82^{\mathrm{c}}$ & $6.72 \pm 1.54^{\mathrm{d}}$ \\
\hline HBL 1:5 & $6.36 \pm 1.82^{\mathrm{a}}$ & $6.21 \pm 1.54^{\mathrm{a}}$ & $6.49 \pm 1.19^{\mathrm{d}}$ & $6.32 \pm 1.49^{\mathrm{c}}$ & $5.18 \pm 1.93^{\mathrm{b}}$ & $6.02 \pm 1.56^{\mathrm{c}}$ \\
\hline
\end{tabular}

Values with the same letter $(\mathrm{a}-\mathrm{c})$ are not statistically different at the $p<0.05$ level (post hoc Tukey's HSD test); data are presented as the means of triplicate measurements \pm standard deviation

panelists' comments, liqueurs with the same proportions of bitter and aromatic plants, as well as with twice as higher amount of aromatic plants extracts, were associated with too intense bitterness interrupting flavor and aroma balance and affecting overall acceptability. However, there were no significant differences $(p<0.05)$ in sensory scores for odor and color among all liqueurs. Also, the satisfaction degree of the consumers' panel with anise flavor and overall acceptability increases with increasing amount of aromatic extracts, but only to some point, since HBL with the highest amount of aromatic extracts was assigned with significantly lower scores for these attributes than the HBL 1:4. Larger standard deviations obtained for anise flavor for HBL 1:4 and HBL 1:5 indicate that consumers are quite divided in opinion on anise flavor, either liking it or not. Based on the highest overall acceptability, the formulation HBL 1:4 is chosen for ideal sweetness determination and comparison of its AO activity with similar commercial products.

\section{Ideal sweetness determination}

Determination of the amount of sucrose to be added in the liqueur selected by consumers as the most acceptable one to obtain the ideal intensity sweetness was carried out. In that regard, five sucrose concentrations, starting with the twice as lower as the minimum regulated for liqueurs $(50 \mathrm{~g} / \mathrm{l})$, were tested. Consumers' perceptions were transformed into numerical data $(-4$ to +4$)$, with the ideal sweetness corresponding to the value of 0 .

Histograms with consumer distributions are shown in Fig. 1. It can be observed that with the increase of sucrose concentration the distribution of the consumers' shifts from the negative to the positive extremes, associated with "not nearly sweet enough"(grade - 4) and "much too sweet" (grade 4). In the case of the sample with $50 \mathrm{~g} / \mathrm{l}$ of sucrose, the consumers' distribution is concentrated in the negative area, related to less sweet than ideal. Samples with $70 \mathrm{~g} / \mathrm{l}$
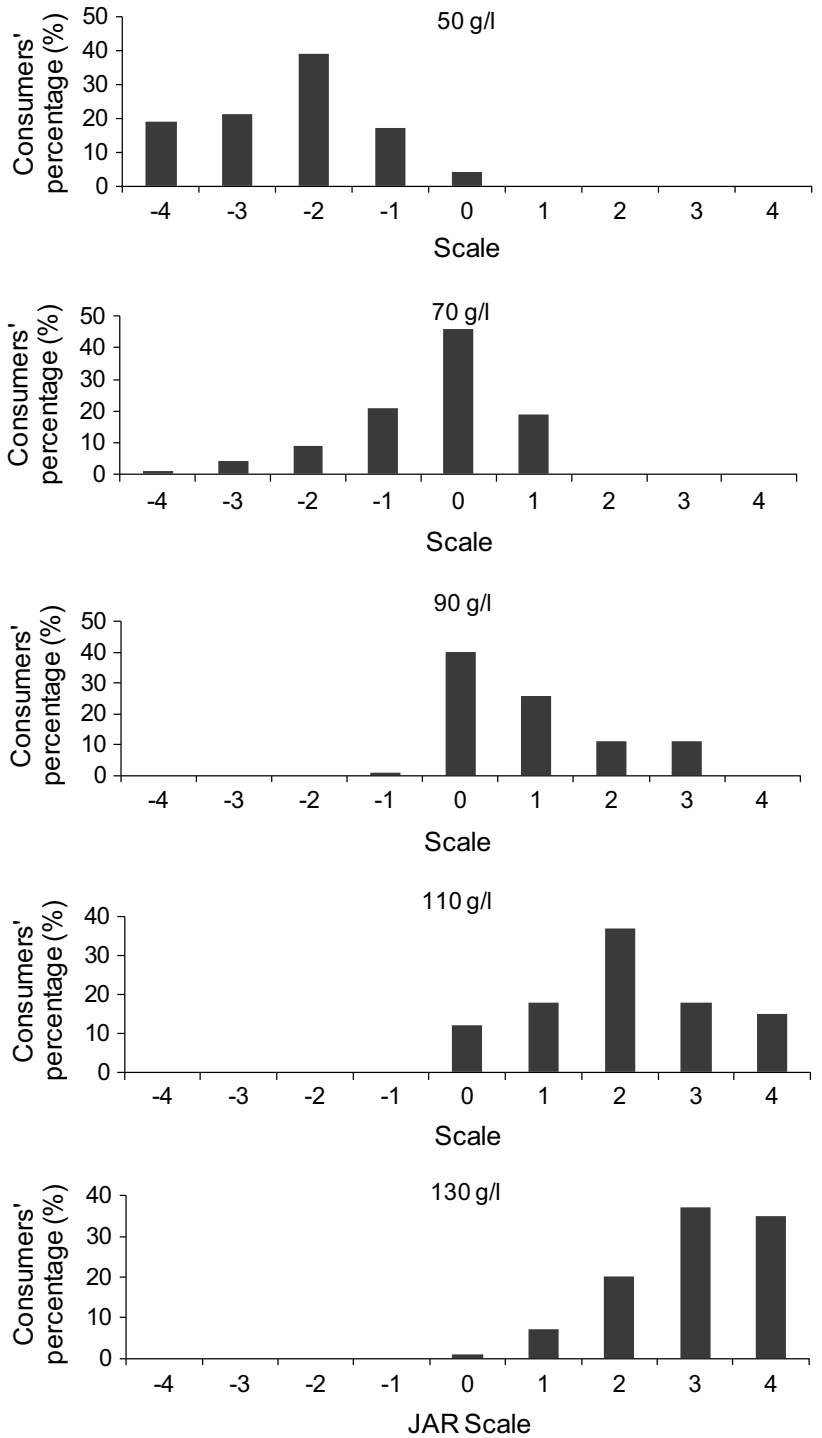

Fig. 1 Histograms with the distribution of responses in the acceptance test for samples with $50 \mathrm{~g} / \mathrm{l}, 70 \mathrm{~g} / \mathrm{l}, 90 \mathrm{~g} / \mathrm{l}, 110 \mathrm{~g} / \mathrm{l}$ and $130 \mathrm{~g} / \mathrm{l}$ of sucrose added 
and $90 \mathrm{~g} / \mathrm{l}$ of sucrose were considered as "just about right" (grade 0 ) by the majority of the consumers, $46 \%$ and $40 \%$, respectively.

Liqueur with $110 \mathrm{~g} / \mathrm{l}$ of sucrose added was associated with "'moderately sweeter" (grade 2), whereas $130 \mathrm{~g} / \mathrm{l}$ sucrose sample was perceived as "much sweeter" (grade 3 ) by the major percentage of the consumers $(37 \%)$.

The linear regression between the means of the JAR values assigned by consumers and each sucrose concentration (Fig. 2) showed that the ideal sweetness in HBL is obtained with the $80.32 \mathrm{~g} / \mathrm{l}$ of sucrose.

Various products have been studied for ideal sweetness using 9 category scale, such as fruit nectars and juice (Cardoso and Bolini 2007; De Oliveira Rocha and Bolini 2015), iced and hot instant tea (Cardoso et al. 2004), instant and roasted ground coffees (Moraes and Bolini 2010). As expected, optimal sucrose concentration varies within the group of similar products and is in relation to the type of product being analyzed. However, to our knowledge, despite containing the high level of sugar added, this is the first study dealing with the ideal sweetness in liqueur. The amount of sugar in many commercial liqueurs reaches even more than $400 \mathrm{~g} / \mathrm{l}$ (Bamforth and Ward 2014), which is rarely specified on the product label. Here, despite containing bitter herbs with intense bitterness, optimal sucrose concentration of HBL was found to be much lower in comparison to the majority of commercial ones and approximately $20 \%$ lower than the minimum stipulated by European Commission. It's worth mentioning at this point that consumers perceptions for HBL with the highest sugar concentration tested (130 g/l), but still much lower than in the most of the commercial liqueurs, was mainly associated "much sweeter" and "much too sweet" (grade 3 and grade 4) by significant percentage of consumers (37\% and 35\%).

There is increasing concern that free sugars, particularly from the sugar-sweetened beverages, contribute to

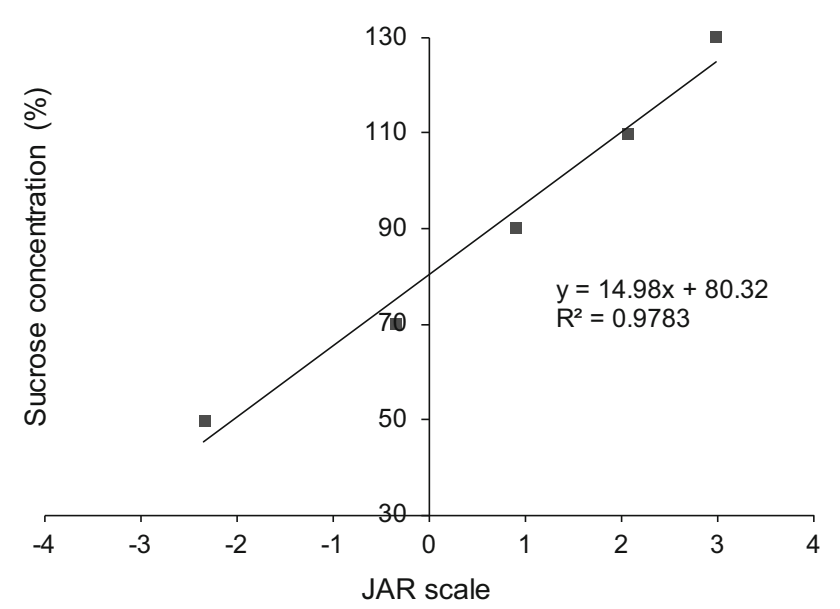

Fig. 2 Ideal concentration of sucrose to be added in HBL promoting a positive energy balance and decreasing the intake of foods with more nutritionally suitable calories, leading to an unhealthy diet and weight gain. This is in relation to the rapidly growing problem with overweight and obesity in the world, as one of the main factors causing chronic diseases, the leading cause of premature deaths. In addition, the association between the intake of free sugars and dental caries has received increasing attention in recent years (World Health Organization 2015). Taking all these facts into account, it's important to give consumers an opportunity to decide about the ideal concentration of sugar to be added in liqueurs, by carrying out sensory analysis before production of this high-calorie spirits. Also, the obtained results suggest that some parts of Regulation (EC) No. 110/2008 concerning the minimum allowed amount of sugar added in some categories of spirits should be revised in the future editions. Consequently, manufacturers of liqueurs would be enabled to, in the consultation with consumers and keeping up with their demands, reformulate existing products or create new ones with lower sugar content, thus contributing to the widening of sugar-reduced products market.

\section{Antioxidant activity of obtained liqueur and comparison with similar commercial beverages}

Widely used spectrophotometric assays FC, DPPH, FRAP and ABTS, were applied to determine TPC and AO capacity of obtained herbal liqueur and to compare it with similar commercially available herbal alcoholic beverages. The following beverages were chosen for comparison:

- "Underberg" - commercial herbal bitter (44\% vol of alcohol).

- "Bitter 54"-commercial herbal liqueur (35\% vol of alcohol), the natural product made from the extracts of 54 aromatic herbs and fruits. Bitter 54 contains $88.22 \mathrm{~g} /$ 1 total extract and $75 \mathrm{~g} / \mathrm{l}$ sugar added. Additive E160d (caramel) was used to gain dark-brown color.

- "Bitter 55" (Ganoderma bitter)—small-scale product (Faculty of Agriculture, University of Belgrade, Serbia) (35\% vol of alcohol) natural product made from Bitter 54 and medicinal mushroom Ganoderma lucidum (1\% w/v). In the bottle of Bitter 54 a slice of mushroom was added and extracted 30 days at ambient temperature.

- "Pervivo"-commercial medicinal tonic ( $40 \%$ vol of alcohol) made of 25 plant species.

- "Jägermeister"-commercial liqueur (35\% vol of alcohol) made of 56 medicinal and aromatic plant species and fruits.

- "Gorki list"-commercial liqueur (28\% vol of alcohol) made from 27 medicinal and aromatic plants with Wormwood as a dominant one. 
Results of TPC and AO activity determination are shown in Table 2.

Herbal bitter liqueur possessing the highest TPC was also found to be the most effective in terms of scavenging DPPH and reducing ability measured by FRAP among all analyzed beverages, followed by Underberg. The total phenolic content of HBL was several times higher when compared to herbal alcoholic beverages from the market, whereas the difference observed among AO assays was even greater. It's interesting that HBL showed pronounced superiority in terms of TPC and AO capacity measured by all assays applied in comparison to Pervivo, digestive herbal remedy, that is found to be effective in case of immunodeficiency conditions (Bałan et al. 2013). The same decreasing rank of order of Bitter 54, Bitter 55, Pervivo and Jägermeister, measured by DPPH assay was obtained by Vukosavljevic et al. (2009), as well as of TPC values for Underberg, Bitter 54, Bitter 55 and Pervivo, measured by FC in study of Gorjanović et al. (2010b).

High TPC of herbal spirits is in accordance with high AO capacity, which is confirmed by regression analysis. Correlations between all applied assays on herbal alcoholic beverages are shown in Fig. 3. Results of all spectrophotometric assays are in correlation at $95 \%$ confidence level, at $p<0.01$ significance level (not shown). High statistically significant correlations between TPC and AO assays indicate that $\mathrm{AO}$ activity of herbal spirits is mainly influenced by TPC. Many studies reported that polyphenols are responsible for AO activity of various food samples, such as culinary and medicinal herbs (Katalinic et al. 2006; Petrovic et al. 2016), herbal infusions (Gorjanović et al. 2012), fruits, vegetables and beverages (Floegel et al. 2011). Imark et al. (Imark et al. 2000) reported a relatively strong correlation between the total polyphenolic content of selected herbal spirits and their radical scavenging ability $\left(r^{2}=0.81\right)$. In the same study, TPC of Underberg (1200 mg CAE/l), showing the highest activity among all spirits, comparable to those of red wine (1400 mg CAE/l), corroborates with our result. Herbal liqueur HBL evidently surpasses some red wines in terms of TPC or is very close
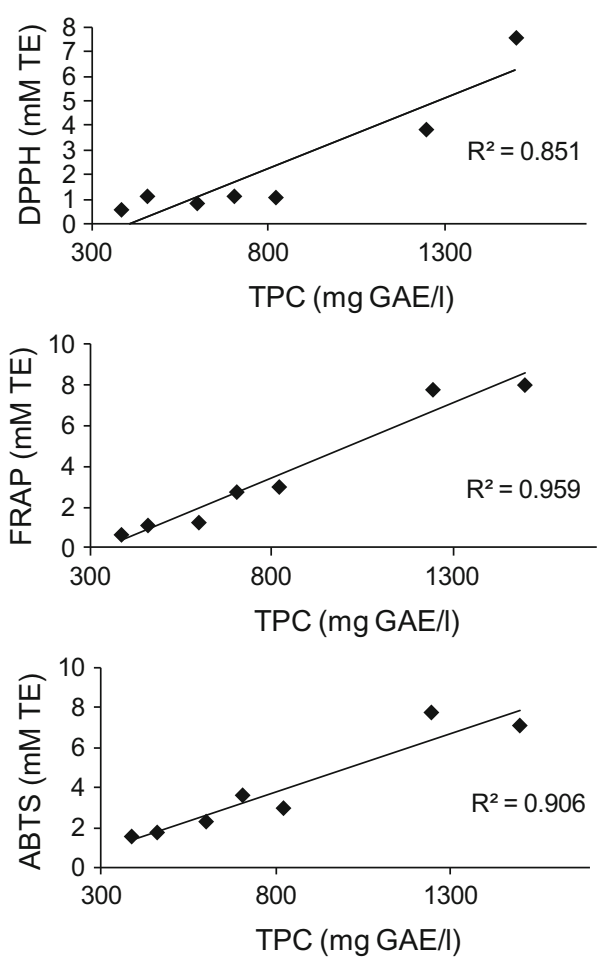

Fig. 3 Relationship between TPC and DPPH, FRAP and ABTS for HBL and commercial herbal spirits

to those values reported by Paixao et al. (2007) for commercial Terras Madeirenses Portuguese red wines (1724-1871 mg GAE/l). Mrvcic et al. (2012) demonstrated that polyphenol content and AO power, determined by FRAP assay of pure distillates, aging distillates, bitters, bitter and fruit liqueurs, were closely correlated. The same authors found that homemade rums and aged distillates were best correlated, followed by bitter liqueurs, fruit liqueurs and bitters. Significant correlations of raki samples TPC with CUPRAC, TEAC and ORAC (0.8071, 0.8196 and 0.7998 , respectively) indicated that phenolic compounds might be among the main components responsible for free radical scavenging ability (Yalcin 2016). Polarographic AO assay based on hydrogen peroxide scavenging (HPS), as well as DPPH and total phenolics for various red
Table 2 Total phenolic content (TPC) and antioxidant capacity of HBL and commercial herbal spirits, measured by spectrophotometric assays (FC, DPPH, FRAP and ABTS)

\begin{tabular}{lclll}
\hline & TPC $(\mathrm{mg} \mathrm{GAE} / \mathrm{l})$ & DPPH $(\mathrm{mM}$ TE) & FRAP $(\mathrm{mM}$ TE) & TEAC $(\mathrm{mM}$ TE) \\
\hline HBL & $1500.25 \pm 48.80^{\mathrm{g}}$ & $7.59 \pm 0.42^{\mathrm{e}}$ & $8.02 \pm 0.25^{\mathrm{f}}$ & $7.10 \pm 0.29^{\mathrm{e}}$ \\
Underberg & $1246.11 \pm 12.51^{\mathrm{f}}$ & $3.85 \pm 0.23^{\mathrm{d}}$ & $7.79 \pm 0.37^{\mathrm{e}}$ & $7.75 \pm 0.22^{\mathrm{f}}$ \\
Bitter 54 & $703.70 \pm 7.29^{\mathrm{d}}$ & $1.13 \pm 0.08^{\mathrm{c}}$ & $2.76 \pm 0.09^{\mathrm{c}}$ & $3.63 \pm 0.03^{\mathrm{d}}$ \\
Bitter 55 & $821.11 \pm 17.00^{\mathrm{e}}$ & $1.08 \pm 0.17^{\mathrm{c}}$ & $3.01 \pm 0.06^{\mathrm{d}}$ & $2.99 \pm 0.01^{\mathrm{c}}$ \\
Jägermeister & $598.89 \pm 35.64^{\mathrm{c}}$ & $0.84 \pm 0.07^{\mathrm{b}}$ & $1.26 \pm 0.10^{\mathrm{b}}$ & $2.32 \pm 0.10^{\mathrm{b}}$ \\
Pervivo & $458.15 \pm 22.07^{\mathrm{b}}$ & $1.13 \pm 0.02^{\mathrm{c}}$ & $1.12 \pm 0.07^{\mathrm{b}}$ & $1.78 \pm 0.02^{\mathrm{a}}$ \\
Gorki list & $384.82 \pm 4.49^{\mathrm{a}}$ & $0.58 \pm 0.08^{\mathrm{a}}$ & $0.66 \pm 0.01^{\mathrm{a}}$ & $1.58 \pm 0.09^{\mathrm{a}}$ \\
\hline
\end{tabular}

Values with the same letter (a-g) are not statistically different at the $p<0.05$ level (post hoc Tukey's HSD test); data are presented as the means of triplicate measurements \pm standard deviation) 
and white wines of different origin and various spirits, were strongly correlated $\left(\mathrm{r}^{2}>0.95\right)$ (Gorjanović et al. 2010a, b).

\section{Analysis of volatile components in HBL}

HS-GC/MS analysis of HBL showed the presence of 29 different compounds (Table 3 ) of which 2 were quantified, methanol $(4.97 \mathrm{mg} / \mathrm{l})$ and ethyl acetate $(8.22 \mathrm{mg} / \mathrm{l})$, whereas higher alcohols were not detected. These compounds derive from the fermentation process and remain after alcohol purification. Methanol occurs naturally at a low level in most alcoholic beverages without causing harm, but it may occasionally reach concentrations that can be a potent toxicant in humans. Although ethyl acetate is unfavorable to spirit quality, giving a nail polish note at high concentrations $(15-20 \mathrm{~g} / \mathrm{hl})$, it also contributes to fruity properties of beverages at low concentration (Cabaroglu and Yilmaztekin 2011). Analysis showed that ethanol was the most abundant compound in the gas phase (79.67\%). The analysis also revealed the presence of

Table 3 Chemical composition (\%) of HBL obtained by HS-GC/MS

\begin{tabular}{lc}
\hline Compound & Content $(\%)$ \\
\hline Methyl acetate & 0.20 \\
Ethyl acetate & 0.58 \\
Methanol & 0.02 \\
2-Methyl-pentanal & 0.12 \\
Ethanol & 79.67 \\
$\alpha$-Pinene & 0.07 \\
Pentyl acetate & 0.06 \\
Myrcene & 0.16 \\
$\beta$-Pinene & 0.06 \\
Terpinolene & 0.05 \\
Limonene & 0.07 \\
Eucalyptol & 3.42 \\
$\alpha$-Terpinene & 0.11 \\
p-Cymene & 0.02 \\
$\gamma$-Terpinene & 0.02 \\
Myrcenol & 0.03 \\
Myrtenol & 0.03 \\
3-(2-Propenyl)-cyclohexene & 2.44 \\
3-Nonyne & 1.37 \\
Menthon & 3.75 \\
Isomenthon & 0.59 \\
-Camphonelal & 1.38 \\
Menthol & 1.89 \\
Borneol & 3.10 \\
Carvone & 0.35 \\
Anethol & 0.20 \\
& 0.09 \\
\hline & 0.17 \\
\hline
\end{tabular}

hydrocarbons (3-nonyne and 3-(2-peopenyl)-cyclohexene), fatty acid ester (pentyl acetate) and terpenes (monoterpenes and sesquiterpenes). The most dominant monoterpenes were menthone $(3.75 \%)$, eucalyptol $(3.42 \%)$ and menthol $(3.10 \%)$, originating from the mentha extract, the most abundant extract in HBL, while of sesquiterpenes only $\gamma$ gurjunene was detected $(0.11 \%)$.

Different studies demonstrated a wide range of biological activity of terpenes e.g. anticancer, antinociceptive, antimicrobial, as well as the antioxidant activity. There is also some evidence that they express beneficial effects on risk factors for cardiovascular disease (Buchbauer 2010). Therefore, besides high polyphenolic content, the presence of terpenes might be an additional explanation for pronounced antioxidant activity of HBL.

\section{Conclusion}

Herbal beverages have been increasingly popular in the food industry due to their beneficial impact on human health, which is related to the bioactivity of plant constituents. New HBL, made from selected bitter and aromatic medicinal plants, was formulated on the basis of hedonic consumers' acceptance test. Sugar content in obtained HBL was optimized according to consumers' perception of ideal sweetness intensity. It was observed that the concentration of sugar added to obtain ideal sweetness was $20 \%$ below the minimum legislated, as well as much lower than in the majority of commercial liqueurs. Therefore, this study supports the development of sugarreduced products market, thus to a certain degree giving rise to the improvement of general public health. Taking into account that food and drink industry should be dynamic, innovative and consumer-oriented industry, the obtained result suggests the need for preliminary sensory research on optimal sweetness before industrial production of liqueurs, whereas legislation should go along with consumers' needs.

Since ethanol-induced diseases may occur as a result of the hydroxyl radicals production during human metabolism of alcohol (Albano 1996), the presence of natural AOs in alcoholic beverages may be beneficial. Herbal bitter liqueur obtained in this study showed superior AO activity and total phenolic content in comparison with similar commercial beverages. Antioxidant capacity of herbal spirits correlated with their TPC. Therefore, although the exact nature of active herbal AOs remains to be determined, phenolic compounds seem to be the key contributors. However, due to the gap between in vitro and in vivo studies, absorption and bioavailability of AOs have not still been completely understood, and the mechanisms of biological interactions and health-promoting activities after 
consumption of alcoholic beverages have still been a challenging area of research.

Acknowledgements The paper is a part of the research done within the Project No. TR 31055. The authors acknowledge financial support by the Ministry of Education, Science and Technological Development of Serbia.

\section{References}

Alamprese C (2005) Characterization and antioxidant activity of nocino liqueur. Food Chem 90:495-502

Albano E (1996) Role of cytochrome P4502E1-dependent formation of hydroxyethyl free radical in the development of liver damage in rats intragastrically fed with ethanol. Hepatology 23:155-163

Bałan BJ, Stankiewicz W, Skopińska-Różewska E et al (2013) Experimental immunology the effect of multi-component herbal remedy Pervivo on cellular immunity and tumor angiogenesis in mice. Cent Eur J Immunol 38:54-61

Bamforth CW, Ward Robert E (2014) The Oxford handbook of food fermentations. Oxford University Press, New York

Benzie IFF, Strain JJ (1996) The ferric reducing ability of plasma (FRAP) as a measure of "antioxidant power": the FRAP assay. Anal Biochem 239:70-76

Blois MS (1958) Antioxidant determinations by the use of a stable free radical. Nature 181:1199-1200

Buchbauer G (2010) Biological activities of essential oils. In: Başer KHC, Buchbauer G (eds) Handbook of essential oils. CRC Press, Boca Raton, pp 241-286

Cabaroglu T, Yilmaztekin M (2011) Methanol and major volatile compounds of Turkish raki and effect of distillate source. J Inst Brew 117:98-105

Cardoso JMP, Bolini HMA (2007) Different sweeteners in peach nectar: ideal and equivalent sweetness. Food Res Int 40:1249-1253

Cardoso JMP, Battochio JR, Cardello HMAB (2004) Equivalência de dulçor e poder edulcorante de edulcorantes em função da temperatura de consumo em bebidas preparadas com chá-mate em pó solúvel. Ciência e Tecnol Aliment 24:448-452

Council of Europe (1999) European pharmacopoeia, 3rd edn. Council of Europe, Strasbourg

De Oliveira Rocha IF, Bolini HMA (2015) Different sweeteners in passion fruit juice: ideal and equivalent sweetness. LWT-Food Sci Technol 62:861-867

European Parliament and Council (2008) Regulation (EC) No 110/2008 of the European Parliament and of the Council of 15 January 2008 on the definition, description, presentation, labelling and the protection of geographical indications of spirit drinks and repealing Council Regulation (EEC) N. Off J Eur Union L39:16-54

Floegel A, Kim DO, Chung SJ et al (2011) Comparison of ABTS/ DPPH assays to measure antioxidant capacity in popular antioxidant-rich US foods. J Food Compos Anal 24:1043-1048

Gorjanović SZ, Novaković MM, Potkonjak NI, Sužnjević DZ (2010a) Antioxidant activity of wines determined by a polarographic assay based on hydrogen peroxide scavenge. J Agric Food Chem 58:4626-4631

Gorjanović SZ, Novaković MM, Vukosavljević PV et al (2010b) Polarographic assay based on hydrogen peroxide scavenging in determination of antioxidant activity of strong alcohol beverages. J Agric Food Chem 58:8400-8406

Gorjanović S, Komes D, Pastor FT et al (2012) Antioxidant capacity of teas and herbal infusions: polarographic assessment. J Agric Food Chem 60:9573-9580
Imark C, Kneubühl M, Bodmer S (2000) Occurrence and activity of natural antioxidants in herbal spirits. Innov Food Sci Emerg Technol 1:239-243

Katalinic V, Milos M, Kulisic T, Jukic M (2006) Screening of 70 medicinal plant extracts for antioxidant capacity and total phenols. Food Chem 94:550-557

Lawless HT, Heymann H (2010) Sensory evaluation of food. Springer, New York

Lee HK, Choi YM, Noh DO, Suh HJ (2005) Antioxidant effect of Korean traditional lotus liquor (Yunyupju). Int J Food Sci Technol 40:709-715

Li W, Beta T (2011) Evaluation of antioxidant capacity and aroma quality of anthograin liqueur. Food Chem 127:968-975

Meilgaard MC, Carr BT, Civille GV (2007) Sensory evaluation techniques, 4th edn. CRC Press, New York

Moraes PCBT, Bolini HMA (2010) Different sweeteners in beverages prepared with instant and roasted ground coffee: ideal and equivalent sweetness. J Sens Stud 25:215-225

Mrvcic J, Posavec S, Kazazic S et al (2012) Spirit drinks: a source of dietary polyphenols. Croat J Food Science Technol 4:102-111

Paixao N, Perestrelo R, Marques J, Camara J (2007) Relationship between antioxidant capacity and total phenolic content of red, rosé and white wines. Food Chem 105:204-214

Petrovic M, Suznjevic D, Pastor F et al (2016) Antioxidant capacity determination of complex samples and individual phenolicsmultilateral approach. Comb Chem High Throughput Screen 19:58-65

Ramchandani VA, Kwo PY, Li TK (2001) Effect of food and food composition on alcohol elimination rates in healthy men and women. J Clin Pharmacol 41:1345-1350

Re R, Pellegrini N, Proteggente A et al (1999) Antioxidant activity applying an improved ABTS radical cation decolorization assay. Free Radic Biol Med 26:1231-1237

Singleton VL, Orthofer R, Lamuela-Raventós RM (1999) Analysis of total phenols and other oxidation substrates and antioxidants by means of Folin-Ciocalteu reagent. In: Methods in enzymology. Academic Press, New York, pp 152-178

Smith AF (2012) The Oxford encyclopedia of food and drink in America, 2nd edn. Oxford University Press, Oxford

Tonutti I, Liddle P (2010) Aromatic plants in alcoholic beverages. A review. Flavour Fragr J 25:341-350

USDA, U.S. Department of Health and Human Services, U.S. Department of Agriculture (2005) Dietary guidelines for Americans, 2005

Veljković VB, Stanković MZ (2003) HERBSlherbs used in alcoholic drinks. In: Caballero B (ed) Encyclopedia of food sciences and nutrition. Elsevier, Amsterdam, pp 3098-3107

Ventura EE, Davis JN, Goran MI (2011) Sugar content of popular sweetened beverages based on objective laboratory analysis: focus on fructose content. Obesity 19:868-874

Vukosavljevic P, Novakovic M, Bukvic B et al (2009) Antioxidant activities of herbs, fruit and medicinal mushroom Ganoderma lucidum extracts produced by microfiltration process. J Agric Sci Belgrade 54:45-62

Wakeling IN, MacFie HJH (1995) Designing consumer trials balanced for first and higher orders of carry-over effect when only a subset of $\mathrm{k}$ samples from $\mathrm{t}$ may be tested. Food Qual Prefer 6:299-308

World Health Organization (2015) Sugars intake for adults and children. WHO, Geneva

Yalcin G (2016) Antioxidant capacity of a turkish traditional alcoholic drink, Raki. Polish J Food Nutr Sci 66:167-171

Publisher's Note Springer Nature remains neutral with regard to jurisdictional claims in published maps and institutional affiliations. 